described by Finberg and colleagues. ${ }^{5}$ Three of the five babies had diarrhoea, and four vomited-two of them vomiting blood-stained mucus-and it was casy to see that the obvious diagnosis was gastroenteritis. Two had rapid respirations and cyanosis, and one had convulsions, thought possibly to be due to hypocalcaemia, as described by L. Finberg aid H. E. Harrison. ${ }^{7}$ They explained the effects of the hypernatraemia on the basis of an increase in the tonicity of the extracellular fluid. All the babies had subarachnoid and intracerebral haemorrhages, with shrinkage of the renal convoluted tubular cells from the basement membrane.

We can all learn from these disasters and try to ensure that no such mistakes are made in the preparation of feeds for babies under our care.

\section{Herpes Gestationis}

Pregnancy upsets the skin in several ways, none more troublesome than by producing itching. Commonly this is without a concomitant rash, but rarely-once in about 4,000 pregnancies followed up in hospital ${ }^{1}$-it provokes a serious and distressing bullous eruption peculiar to pregnancy known as herpes gestationis.

Though it may start as pruritus without signs, ${ }^{2}$ it soon progresses to plaques of erythema and oedema and then to tense vesicles and bullae, mostly on the limbs, but the centre of the abdomen is often affected. Starting in the latter half of pregnancy, though not necessarily in the first pregnancy, it resolves early in the puerperium, only to recur in each subsequent pregnancy. There is no relation to the sex of the fetus or to the age of the mother, nor does it disturb the pregnancy, labour, or puerperium except by adding greatly to the woman's discomfort. An evanescent eruption has been reported in the newborn infant. ${ }^{3}$

In its early stages it needs to be distinguished from other causes of pruritus such as urticaria, scabies, drug reactions, and eczema, but with the appearance of bullae the doctor needs to consider dermatitis herpetiformis, erythema multiforme, bullous pemphigoid, and drug eruptions. Dermatitis herpetiformis differs in distribution-mostly on buttocks, shoulders, scalp, knees, and elbows ; in its chronic, relapsing course unrelated to pregnancy ; in its appearance consisting of transient small vesicles and excoriations; and in response to therapy, for dapsone regularly suppresses it. Erythema multiforme mostly affects the extremities, rarely itches, and usually lasts only two weeks; while bullous pemphigoid is a disease of the over-50s, but otherwise resembles it closely.

The relationship of herpes gestationis to other bullous diseases has always been disputed. J. B. H. Bunel in $1811^{4}$ first described the disease as a form of pemphigus, and J. L.

\footnotetext{
Russell, B., and Thorne, N. A., British Jouinal of Dermatology, 1957, 69, 339.

69, 339. Wilkinson, D. S., and Ebling, F. J. G., Textbook of

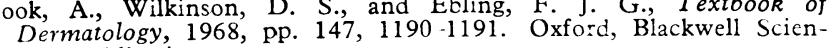
tific Publications.

${ }^{3}$ Kolodny, R. C., Amsrican Fournal of Obstetrics and Gynecology, 1969,

104, 39.
Bunel, J. B. H., Essai sur le pemphigus, 1811. Paris.

- Milton, J. L., The Pathology and Treatment of Diseases of the Skin, 1872 , p. 205 . London, R. Hardwicke.

- Shapiro, A. L., Archives of Dermatology, 1966, 94, 246.

7 Coupe, R. L., Archives of Dermatology, 1965, 91, 633.

- Lynch, F. W., and Albrecht, R. J., Archives of Dermatology, 1966, 93,

446. W. B., Preucel, R. W., and Spoont, S. S., Fournal of the
Shelley, W. B. American Medical Association, 1964, 190, 35.
}

Milton in $1872^{5}$ devised its current title, though no one now regards it as being caused by a virus. Comparisons with dermatitis herpetiformis, erythema multiforme, and bullous pemphigoid serve only to emphasize the uniqueness of herpes gestationis. It resemb $b^{1} \sim s$ bullous pemphigoid of the elderly in its acute onset and predictable remission, its resistance to dapsone, and its good response to systemic steroids; so it might be regarded as a similar reaction pattern but precipitated by a different stimulus.

Systemic steroids are the most satisfactory treatment. A dose of $30 \mathrm{mg}$. prednisone daily is usually sufficient to suppress the eruption. This is a relatively safe treatment, since it is required only in the latter half of pregnancy, but special supervision of parturition may be needed. Steroids are sometimes ineffective, and then pyridoxine in pharmacological dosage-400 to $600 \mathrm{mg}$. in divided doses by mouth -has been effective. ${ }^{7}$ Topical therapy is usually useless, apart from the temporary relief afforded by antipruritics such as crotamiton.

No satisfactory explanation for the development of this dermatosis has been offered. Recently provocation of herpes gestationis by progestational steroids used for contraception has been reported, ${ }^{8}$ and a similar eruption called autoimmune progesterone dermatitis was shown to be provoked by moderate doses of progesterone and cured by oophorectomy. ${ }^{9}$ This has provided some evidence that endogenous progesterone may have a role in the causation of herpes gestationis, but more reports on the effect of progestational steroids on this disease are awaited.

\section{Racial Muddle}

The doctor who advertised for a "Scottish daily for Scottish family" has stirred up something of more importance to the medical profession than the flavour of porridge. It seems that the Race Relations Act contains an anomaly by which it is legal in some circumstances to offer employment to people selected by race or national origin, but illegal to advertise it. The British Medical fournal is advised that it has unwittingly fallen into this trap at least once.

For one reason or another some hospital appointments in Great Britain are reserved for doctors from the Commonwealth. The intention here is to provide teaching facilities to people who cannot get them in their own country. In this way the best features of British medicine are transmitted to doctors abroad, especially in the developing countries. Some posts of this kind entail the selection of people of particular nationalities. In short, there are posts which are legal under the Act but cannot be advertised without breaking the law.

Racial discrimination is wholly contrary to the traditions and practice of medicine, and this is not the place to comment on whether or not the Race Relations Act fulfils its intentions. Certainly every medical man ought to agree with them, for they are to prevent discrimination against another person " on the ground of colour, race or ethnic or national origins." But it would be unfortunate if a few zealots start using an imperfectly worded statute to impede the educational opportunities that B-itain can offer our co:leagues from overseas. 